\title{
Interdição e invisibilidade nas representações cinematográficas: a geográfica doméstica das empregadas em Que horas ela volta? e Aquarius ${ }^{1}$
}

\author{
Maurício de Bragança' \\ https://orcid.org/0000-0003-4114-9998 \\ Tatiana Oliveira Siciliano" \\ https://orcid.org/0000-0002-7625-0554 \\ Licia Marta da Silva Pinto \\ hhttps://orcid.org/0000-0001-7576-6631

Resumo: O emprego doméstico se configurou historicamente como um espaço de permanência de práticas coloniais, atravessado por hierarquias da ordem de gênero, classe social e identidades étnico-raciais. Produto direto da escravidão e organizado às margens das relações trabalhistas, a profissão é marcada por preconceitos sociais e econômicos. A agente social, empregada doméstica, foi representada pelo cinema e TV como coadjuvante e subalterna, ocupando um lugar periférico e silenciada pelas relações de poder que caracterizavam o espaço da família burguesa. Recentemente alguns filmes nacionais têm problematizado o local ocupado pela doméstica dentro do lar. A partir de uma reflexão sobre espaços, territórios e mobilidades, pretendemos abordar neste artigo dois filmes que mostram as tensões na relação entre empregadas e patroas na casa/família, Que horas ela volta? e Aquarius.

Palavras-Chave: empregada doméstica; cinema brasileiro; mobilidade; regimes de visibilidade.

Abstract: interdiction and invisibility in cinematographic representations: the household geography of the housemaid at Que horas ela volta? and Aquarius - Household employment has been

1 Uma versão deste trabalho foi apresentada ao Grupo de Trabalho Cultura das Mídias do XXVII Encontro Anual da Compós, Pontifícia Universidade Católica de Minas Gerais, Belo Horizonte - MG, 05 a 08 de junho de 2018. 
historically configured as a space of colonial practices, crossed by hierarchies of gender, social class and ethnic-racial identities. A direct product of slavery and organized on the margins of labor relations, the profession is marked by social and economic prejudices. The social agent, the maid, was represented by the cinema and TV as secondary and subordinate, occupying a peripheral place and silenced by the relations of power that characterized the space of the bourgeois family. Recently some national films have discussed the place occupied by the maid within the home. From a reflection on spaces, territories and mobilities, we intend to address in this article two films that show the tensions in the relationship between maids and employers in the home / family, Que horas ela volta? and Aquarius.

Keywords: housemaids; Brazilian cinema; mobility; visibility regimes.

\section{Introdução}

Cena de piscina em uma residência abastada com criança de boia correndo ao redor. Em quadro, moça de rabo de cavalo vestida de branco brinca com um cachorro e, carinhosamente, joga um brinquedo na água. Sugere a Fabinho (o nome do menino) que entre na piscina e salve o bichinho. O menino pergunta se ela também vai entrar, e disfarça constrangida: "Ih, não tenho maiô para nadar". Sentada na cadeira do conjunto de piscina, Val, a moça que cuida da criança, fala ao telefone enquanto olha Fabinho. Pede a uma pessoa (não identificada) para que sua filha atenda ao telefone, alegando que "mainha está morrendo de saudade". Consegue falar com a filha. Desliga dizendo que a ama. Fabinho sai da piscina e pergunta: "Quem você disse que ama?" Val responde, enxugando Fabinho: "Minha filha". Segue o diálogo: - "Onde ela está?", - "Ih, ela tá lá longe". - "E mamãe, cadê?" - "Sua mãe está trabalhando, amor". - "Que horas ela volta?" "Sei não", responde, abraçando e beijando a criança.

Assim começa Que horas ela volta?, dirigido por Anna Muylaert em 2014 e lançado em 2015, dentro de um quadro político otimista, que vislumbrava um Brasil com diminuição da pobreza e maior inclusão social ${ }^{2}$. Conta a história da empregada doméstica Val (Regina Casé), há anos trabalhando e dormindo na casa de uma família da elite paulistana. Val cuida de Fabinho (Michel Joelsas), filho da patroa, para que ela trabalhe, enquanto deixa sua filha no interior de Pernambuco com parentes. Fabinho está prestando vestibular, assim como a filha de Val, Jéssica (Camila Márdila), que está indo a São Paulo para tentar uma vaga na FAU/USP. Sem nunca ter tido uma casa sua, Val recebe Jéssica na residência dos patrões. O fato da jovem não se sentir, como ela mesma declara, "uma cidadã de segunda classe", desnuda uma cena naturalizada nas relações desiguais: a existência de empregadas em meio à presença de uma forte demarcação territorial, habitando a fronteira social em um espaço do convívio íntimo, o lar.

2 Sobre esta discussão ver o artigo de Ligia Lana (2016) e a entrevista com Anna Muylaert em Brasil de Fato. Disponível para download em: https://www.brasildefato.com.br/node/32965/. Acessado em 18/01/2018. 
Vemos um apartamento amplo e bem decorado. É a casa da jornalista e escritora Clara (Sonia Braga), 65 anos, protagonista do filme Aquarius, dirigido por Kléber Mendonça Filho, de 2016. Na sala, estão seus familiares de diferentes gerações: sobrinho com noiva, cunhada e irmão que procuram fotos para o casamento do filho. As lembranças surgem a cada álbum. Em uma delas aparece o marido falecido de Clara, com um de seus filhos, e uma mulher negra com uniforme branco, ao fundo da imagem. Não se vê bem o rosto, mas os signos estão lá: a roupa branca, o lenço na cabeça e a postura corporal encolhida da moça identifica sua função de empregada da família. Clara olha para o irmão e fala: "Aqui, essa mulher, lembra? Qual é mesmo o nome dela?". Em outra foto do marido falecido com a filha, a mulher negra de branco aparece de corpo inteiro, mas ainda sem definição, ao fundo. Clara continua: "Fazia uma comida maravilhosa. Todo mundo adorava ela, lembra?". Vemos outra fotografia com a mulher negra de branco e lenço na cabeça, sorridente, com o bebê no colo e o pai da criança em frente. Clara prossegue: "E essa filha da puta roubou nossas joias, roubou as joias da mamãe, lembra?". Outra foto da menina e a empregada apenas aparece do pescoço para baixo. Seu rosto é cortado do enquadramento. Destaca-se a cor da pele negra contrastando com o branco do uniforme. Clara continua: "Essa aqui escafedeu para o Ceará e nunca mais ninguém viu". Close na cunhada, que toma a palavra: "É, mas é inevitável. A gente explora elas, elas roubam a gente de vez em quando e assim vai, né?". Corta para outra foto da empregada negra agora com o rosto, embora não nítido, por estar fora de foco. Clara responde. "Você está certa. Como era o nome dessa criatura?". Na mesma cena, se vê ao fundo, na cozinha, alheia às reminiscências familiares, a empregada Ladjane (Zoraide Coleto), com Clara há 19 anos.

Filmes, telenovelas e propagandas brasileiras costumam acrescentar as empregadas domésticas à cena familiar brasileira. Sempre ali, uniformizadas, ao fundo, desfocadas, coadjuvantes negras ou mestiças que servem aos atores principais brancos, de elite. Elas são invisíveis aos olhares desatentos, configurando-se como elementos de uma paisagem cotidiana, atravessada por sistemas simbólicos que contribuem para assegurar a "dominação de uma classe sobre a outra (violência simbólica)" (BOURDIEU, 2000, p. 11). Relações de trocas afetivas e financeiras entre mulheres em condição assimétrica que encobrem uma reprodução hierárquica e estratificada (BRITES, 2007). Herança do passado colonial e escravagista, que convive lado a lado com as aspirações modernas na desigualdade brasileira. Se no passado o lugar social era determinado no nascimento, "no mundo moderno os privilégios continuam a ser transmitidos por herança familiar e de classe, [...] mas sua aceitação depende de que os mesmos 'apareçam', agora, [...] como produto 'natural' do 'talento' especial, como 'mérito' do indivíduo privilegiado" (SOUZA, 2009, p. 42). A desigualdade, assim, torna-se justa, por se acreditar fruto de meritocracia.

Há dois pontos importantes na cena cotidiana do emprego doméstico: a) o lócus do trabalho é o lar, local de intimidade entre membros da família, o que coloca a empregada, ao mesmo tempo, em uma posição de proximidade física e distância social mais acentuada; 
b) mesmo que o emprego doméstico no país esteja regido por leis trabalhistas (PEC 66/2012) que garantem à categoria direitos básicos, como salário mínimo, jornada de 44 horas semanais, pagamento de horas extras, o lar não é uma empresa .

No centro está a figura da empregada doméstica que, frequentemente, é atravessada por opressões interligadas ${ }^{3}$ (DAVIS, 2016). Ou seja, não se trata de uma personagem perpassada somente pela questão do gênero (mulher), assim como a patroa, mas também pelas questões étnico-raciais (geralmente negras) e sociais (sem recursos financeiros e com baixo grau de instrução), se constituindo assim numa "tríade minoritária" (DA SILVA PINTO, 2017). Esta agente social assume as tarefas domésticas de um lar que não é seu, para que os membros da família desempenhem tarefas mais valorizadas. O papel de patrão geralmente é exercido por outra mulher, configurando-se em um encontro feminino assimétrico, mas permeado por ambiguidades afetivas (KOFES, 2001; SILVEIRA, 2014; BRITES, 2007).

Nos filmes, notamos que apesar desta relação trabalhista ser "suavizada" através de contornos de proximidade, afeto e intimidade, como em Aquarius, a hierarquização e a invisibilidade das personagens se mostram latentes, seja através dos espaços por onde elas transitam e residem, ou pela demarcação de elementos que estão na própria imagem fílmica, fazendo com que a territorialidade se apresente como um elemento importante na relação representada. Vemos que as personagens patroas promovem, através de suas práticas, um distanciamento seguro das empregadas, demonstrando assim uma "hierarquia enraizada e o medo racializado de 'mistura' e 'contaminação' por um grupo social 'mais baixo'." (MAICH, 2015, p. 147).

Por mais que a empregada seja vista como esse Outro, inferior e que promove um risco de contaminação, ela ainda é necessária para que os serviços de manutenção do lar (também vistos como inferiores) sejam realizados. Por conta disso se instaura uma proximidade compulsória (FIGUEIREDO, 2012) dentro de um espaço doméstico/íntimo, na qual se erguem fronteiras e barreiras, físicas e simbólicas, que regulam a relação com o Outro. A casa converteu-se nesse espaço que abriga zonas periféricas que demarcam as tensões decorrentes das relações entre patroa e empregada, a partir das áreas delimitadas de circulação, exclusão e pertencimento destes agentes, a exemplo do que ocorre nas megalópoles ocidentais (FIGUEIREDO, opus. cit.).

Vemos nos filmes cenas que se referem à diferenciação da comida (qualidade e quantidade da mesma), dos espaços onde as empregadas circulam, dentro e fora de casa, seus lazeres, sua subjetividade e afeto familiar. Todos esses elementos representam a marcação e reforço do papel social a que foram submetidas dentro de uma relação fortemente hierarquizada.

3 Segundo dados da Fundação Seade e do Dieese (2014), 96,5\% de mulheres ocupavam o cargo de empregadas domésticas, dentre estas 52,6\% eram negras (DA SILVA PINTO, 2017). 


\section{Resíduos de uma relação colonial}

O emprego doméstico no Brasil historicamente se configurou como um espaço de permanência de práticas coloniais, atravessado por hierarquias da ordem de gênero, classe social e identidades étnico-raciais. A casa e seus espaços traduziam para o microcosmo doméstico as tensões e assimetrias estruturantes da sociedade colonial. Nesse sentido, podemos pensar de que maneira a relação entre a empregada doméstica, a patroa e os demais membros da família repercute na disputa de territórios e os lugares que cada um/a deveria ocupar na formação social do país, inserindo tais espaços de poder num contexto ainda maior, se pensarmos essa configuração no interior de uma ordem capitalista internacional.

É nessa chave que convocamos a ideia lançada por Anibal Quijano ao constatar que, no seio do processo colonial, a América gestou um novo padrão de poder mundial a partir de dois eixos: de um lado, a diferença estabelecida através da categoria étnico-racial, localizando determinados grupos sociais em situação de inferioridade, naturalizada ao longo das práticas de sujeição e opressão cotidianas, que tornam o racismo um importante operador de diagnóstico e controle social. Combinadas a este aspecto, as relações coloniais desenvolveram-se no bojo da formação histórica do controle do trabalho, bem como de seus recursos e produtos, pela afirmação do capital e do mercado que se expandia (QUIJANO, 2005).

Essa estrutura, legitimadora de produção de conhecimentos (eurocentrismo) e organizadora das relações sociais instauradas pelos processos de dominação, manteve-se ao longo da história através de práticas que consolidam aquilo que Quijano nomeia como "colonialidade do poder". Assim, em linhas gerais, os diversos grupos sociais acabaram ocupando um determinado lugar no sistema produtivo de trabalho a partir de operadores sociais que combinavam racismo e sexismo.

Esta é uma perspectiva de análise que nos inspira a observar de que maneira o trabalho doméstico mantém-se organizado nesse mesmo padrão colonial, a despeito de toda conquista efetivamente consolidada pelo reconhecimento desse tipo de atividade no estatuto dos direitos trabalhistas acolhidos pela legislação ${ }^{4}$. A PEC 66/2012 acolheu uma reivindicação fruto de um já antigo ativismo das empregadas domésticas, mas ela não desmobilizou aquilo que conformou as assimétricas relações sociais pautadas pelos princípios racistas e sexistas que a colonialidade do poder evoca. Podemos, então, pensar no trabalho doméstico a partir deste conjunto de categorias sociais, que ajudou a distribuir os papéis que cada um/a desempenharia nessa organização social, definindo simultaneamente o lugar que cada uma destas identidades históricas ocuparia na sociedade ${ }^{5}$.

4 É importante ressaltar que a máquina governamental, desde 2016, vem se estruturando em prol da fragilização e destituição de várias garantias trabalhistas, colocando em risco o aparato legal que historicamente amparou as diversas categorias de trabalhadores no Brasil. Devemos ainda atentar para o fato de que muitas atividades, executadas sobretudo por trabalhadores e trabalhadoras negras, nem chegavam a ser contempladas pelos aparatos legais.

5 Anibal Quijano (2005,p.118) aponta que ao lado da categoria racial, também a ideia de gênero, se estabeleceu como outro instrumento de dominação social universal imprescindível para legitimar as práticas de relações de superioridade/inferioridade na nova estrutura global de controle do trabalho. Estes elementos associados se reforçam mutuamente. 
Percebemos que noções como hierarquia, lugar e papel social são articuladoras dessas discussões, o que nos leva a ideias como espaço, território e mobilidade como forma de problematizar as tensões decorrentes destas relações coloniais, sobretudo no campo da representação a que este artigo se dedica. Compreendemos que uma percepção espacial pode nos ajudar a situar as disputas políticas que estes filmes apontam, enfatizando os circuitos de interdição/mobilidade que estas personagens experimentam. Nessa mesma chave, podemos perceber como estas personagens das empregadas domésticas desenvolvem formas de pertencimento a determinados territórios proporcionando simultaneamente um empoderamento e a explicitação de espaços de enfrentamento em torno das geometrias de poder (MASSEY, 2001) constituídas no interior da casa e da relação com a cidade como um todo. Desse modo, os ambientes da casa (e sua arquitetura reveladora das práticas de interdição de mobilidade e instauradora de hierarquias sociais) assim como a circulação da personagem pelos espaços da cidade também apontam para uma construção de sentidos de lugares (geográficos, sociais, discursivos) que desvelam as relações de poder e demarcam as tensões da sociedade brasileira.

Também para Doreen Massey (2001) a raça e o gênero são duas categorias determinantes para a nossa compreensão e experiência de espaço, lançando uma questão crucial ao nos debruçarmos sobre os filmes: "o que determina nossos níveis de mobilidade e influencia o senso que temos do espaço e do lugar?" (MASSEY, 2001, p. 178). Isso evidencia uma dinâmica instauradora dos fluxos na casa na qual se inserem a empregada, a patroa e os demais membros da família, e que denota o já evocado conceito de "geometria do poder".

Podemos apreender que a geometria do poder tem um impacto fundamental na instauração dos fluxos e mobilidades na sociedade, não apenas definindo lugares, permanências e trânsitos nos variados espaços (caracterizados como macro ou microterritórios), mas sobretudo nas relações de poder que operam as interdições ${ }^{6}$. Essa ideia é importante para analisarmos a arquitetura dos espaços domésticos reproduzidos nos filmes e as relações de hierarquia que eles constroem a partir dos procedimentos da linguagem cinematográfica.

Nessa mesma direção, Rogério Haesbaert (2014, p. 6) nos lembra que "a mobilidade se torna um componente central e indissociável dos processos de territorialização", nos ajudando a pensar que os espaços da casa se constituem em territórios, lugares de disputa nos quais os sentidos são produzidos a partir de relações de poder. A partir de Haesbaert, pensamos em territórios em seu aspecto mais zonal, por meio de conceitos como superfície, contiguidade e coesão capazes de delimitar fronteiras organizadas pela ação de forças centrípetas que impõem uma ordem territorial (enraizamento); mas também pensamos em territórios pela perspectiva das descontinuidades, dos fluxos

6 O que não quer dizer que os diversos grupos sociais não criem suas próprias estratégias para pressionar a circularidade instituída pelos poderes. 
cambiantes, dos deslocamentos, das instabilidades, e de forças centrífugas que promovem um des-ordenamento territorial (desenraizamento). Neste aspecto, território perde sua pretensão de estabilidade e assume uma dimensão mais fluida, podendo acolher novas formas de pertencimento, afeto e adesão.

Essas abordagens problematizadoras da ideia de território nos permitem perceber que o trânsito da empregada doméstica pelos espaços compartilhados da casa assume diversos significados a partir de sua relação com a patroa, por exemplo, ou com os filhos da família, com os quais ela pode desenvolver afetividades muito mais complexas e ambíguas $^{7}$. É esse des-ordenamento espacial que pretendemos reforçar neste argumento, capaz de ressignificar espaços e evidenciar tensões, antes dissimuladas pela aparente organização das fronteiras territoriais.

O des-ordenamento (com hífen) envolveria, então, práticas políticas de transformação territorial, abordadas sempre a partir dos sujeitos que as promovem, o que inclui tanto o ordenamento hegemônico quanto o subalterno ou contrahegemônico. A desordem não seria o oposto da ordem, mas uma espécie de sua face "não conservadora", no sentido da mudança que ela pode promover, tanto num sentido positivo quanto negativo[...] (HAESBAERT, 2014, p. 6).

Essa lógica zonal associada aos deslocamentos é o centro da questão no filme de Muylaert, preocupada em politizar os espaços traçados pela arquitetura da casa e da cidade. É através dos espaços que as tensões explodem, desde a câmera que insiste em se posicionar no interior da cozinha, revelando apenas uma parcela do espaço da sala e constituindo um ponto de vista particular na narrativa (instaurado pela lógica zonal mais definitiva: "o espaço de lá e o espaço de cá"8), até o interesse de Jéssica, filha da empregada, por arquitetura (ela está em São Paulo para prestar vestibular para arquitetura na USP), pela distribuição dos espaços, e suas implicações sociais. É ela quem transgride as normas (come o sorvete não permitido para empregados, faz a dona da casa servir-lhe o suco), invade os espaços interditados (a piscina, o quarto de hóspedes, a FAU) e denuncia o desenho da estrutura do poder que mantém seu aspecto colonial ${ }^{9}$.

Enquanto Jéssica se desloca pela casa, sem respeitar os espaços de interdição vestígios da colonialidade do poder -Val cumpre o itinerário que essas relações de poder previamente construíram. Durante a festa de aniversário de Bárbara, a câmera acompanha o deslocamento da empregada pela sala, a servir os convidados. De costas e com a cabeça fora de quadro, vislumbra-se apenas seu gesto de abaixar-se para servir

7 Não discutiremos aqui as relações que se estabelecem com o marido da patroa e que, frequentemente, se constituíram, ao longo da história, em relações marcadas pelo assédio e violência sexual.

8 É importante lembrar a orientação final que Bárbara (Karine Teles), a patroa, dá a Val no auge do conflito com Jéssica: a menina deve ficar "da porta da cozinha pra lá", explicitando os dois territórios radicalmente intransponíveis.

9 Jéssica mostra para a mãe a distribuição espacial dos cômodos e enfatiza a localização do quarto de empregada no pavimento inferior, embaixo do nível da casa. 
àqueles que jamais olham para a personagem, afirmando sua invisibilidade social. Assim é com todos os convidados, até que chega à mesa de Fabinho e seus amigos, quando a personagem entra em quadro e é bem recebida pelo grupo de jovens, expondo elementos da complexa relação entre ela e o menino, que mistura subalternidade e intimidade.

Em Que horas ela volta?, o espaço da mesa de jantar é interditado aos empregados. Val repreendia Jéssica a cada momento que a filha insistia em sentar-se à mesa da sala. O mesmo não pertencimento à sala de jantar também está presente em Aquarius. Na década de 1980, na festa de aniversário de Tia Lúcia (Thaia Perez), de quem Clara herda o apartamento, as empregadas, entregues a seus afazeres, apenas deixam a cozinha para cantar parabéns, espremidas no limiar entre a cozinha e a sala. No filme, o afeto entre patroa e empregada complexifica a relação. Clara nunca deixa de levar algo de comer ao porteiro, de servir um cafezinho ao operário que pinta a fachada do prédio, de manifestar seu apreço por Ladjane. A relação de Clara e Ladjane é pautada por estes dois aspectos: Clara beija o rosto de Ladjane e Ihe entrega uma xícara para que leve para a cozinha. Subordinação e afeto, permeadas por "ambiguidades afetivas" (BRITES, 2007), a boa patroa é aquela que provê, mas que também é a autoridade.

A questão espacial é crucial em Aquarius, cuja narrativa se desenvolve em torno ao direito de Clara permanecer no único apartamento de um prédio antigo que ainda não fora vendido para uma grande construtora, interessada em erguer no local um moderno edifício $^{10}$. O prédio se situa na praia do Pina, lugar valorizado na cidade de Recife. O aspecto zonal do território destacado por Haesbaert (2014) e presente em Que horas ela volta? na precisão dos limites "do lado de cá" e "do lado de lá" exposto mais acima também surge nos lugares onde moram Clara e Ladjane. Numa caminhada pela praia, quando ia "dar um abraço" em Ladjane no dia de seu aniversário, Clara explica à namorada de seu sobrinho como distinguir os limites entre Pina e Brasília Teimosa. São dois bairros contíguos que se localizam à beira da mesma extensão de praia, o primeiro, porém, abastado e valorizado; o segundo, popular e periférico. De acordo com Clara, as partes rica e pobre são divididas por um duto que faz desaguar esgoto na praia. Clara, evidentemente, mora no Pina; Ladjane, em Brasília Teimosa.

Na festa de aniversário, na laje da casa de Ladjane, Clara, afetuosa, apresenta a família da empregada à namorada do sobrinho: "Lala é irmã de Ladjane. Lala trabalha para uma amiga minha e Ladjane trabalha para mim", fazendo repercutir uma tradição colonial da dedicação das mulheres das famílias mais pobres ao trabalho doméstico na casa das sinhazinhas, socializadas para cumprirem o papel de mulher-patroa (ALMEIDA, 1982) na qual "os atos de mandar incorporam-se cedo" (p. 189). Clara é uma intelectual, faz parte de uma família abastada de mulheres emancipadas dedicadas ao mercado de

10 A resistência de Clara contra o modelo de cidade único e neoliberal (GOMES e SICILIANO, 2017) foi aplaudida pelas plateias em 2016, em ocasião do impeachment da presidenta Dilma Roussef. Contudo, o filme ainda aponta a naturalização das relações de classe. 
trabalho, politicamente esclarecidas e implicadas com um discurso progressista, mas que se inserem, pela tradição de classe, nos processos de permanência de práticas coloniais. Trata-se de um desmapeamento - definido por Sérvulo Figueira (1987) como coexistência de mapas contraditórios - comuns em uma sociedade que convive simultaneamente com aspirações e concepções modernas e práticas e comportamentos arcaicos.

Uma das cenas mais desconcertantes e reveladoras desta relação entre patroa e empregada no filme se dá quando Clara revê fotos antigas de família. Enquanto todos se divertem na sala, revendo as fotografias, Ladjane entra em cena para servir vinho, e seu corpo ocupa apenas parte do quadro, exatamente como na cena da festa do filme de Muylaert descrita anteriormente. Ao ver o momento de exposição de fotos de família, sente-se à vontade para mostrar a todos a foto do filho que ela carrega na carteira, morto no ano anterior, vítima de atropelamento. O silêncio que se instaura, enquanto ela apresenta a imagem à família, é constrangedor. A história pessoal de Ladjane não faz parte do espaço da família de Clara, como já repercutiam as fotografias citadas mais acima, nas quais as empregadas apresentavam-se apenas como um espectro da cena principal. A empregada parece ter extrapolado as fronteiras dos dois territórios, trazendo tensão à cena e evidenciando os limites do afeto entre as duas: a dor de Ladjane não cabe naquela sala da família de Clara.

Empregadas domésticas por compartilharem um espaço íntimo familiar recebem a denominação de "como se fosse da família", mas se espera que saibam o "seu lugar". Sua família e seus dilemas não importam para os patrões, mas elas participam das vidas e da criação das crianças como se fossem delas. Sujeitos sem singularidade, quanto mais invisíveis melhor. Val, em Que horas ela volta?, acolhe Fabinho, que conta suas frustrações para a empregada que o criou e lhe deu afeto, tendo uma relação distanciada com a própria mãe. É no estreito quarto de Val que o adolescente vai buscar cafuné e carinho materno, em suas crises e insônias. Ao comunicar à patroa que a filha vem para São Paulo prestar vestibular, Bárbara pergunta quem é Jéssica. Nunca se interessou em conhecer melhor o drama de sua empregada, que migrou para o Sudeste e deixou a filha aos cuidados de parentes. Como retribuição, diz a Val que pode comprar um colchão bom para a filha ficar no quarto da empregada o quanto quiser, porque Val é "quase como fosse da família", pois ajudou a criar Fabinho. No entanto, em um momento de irritação, a patroa diz que Jéssica só poderia ficar no espaço entre a cozinha e as dependências de serviço.

\section{A arquitetura dos lares: reprodução e materialização das fronteiras sociais}

O quarto de empregada, cômodo sempre presente nos apartamentos antigos, mesmo pequenos e não luxuosos, demarca a posição do emprego doméstico no domicílio e como ela se materializa arquitetonicamente. Que Horas Ela Volta? retrata a personagem que 
dorme no serviço e, portanto, várias cenas são passadas no quarto de empregada. É no quartinho apertado que se dá o diálogo entre Val e Jéssica, enfatizando a precariedade do ambiente e a relação de exploração à qual Val está submetida.

Jéssica: Não dá pra abrir a janela, não, Val? Calor da gota...

Val: Se eu abrir a janela vai fazer o mesmo calor, só vai fazer entrar mosquito.

Jéssica: Sinceramente, Val, eu não sei como é que tu aguenta, visse?! [...] Ser tratada desse jeito que nem uma cidadã de segunda classe. Isso aqui é pior que a Índia! Val: Não vem com essas conversas difíceis, negócio de Índia, não. Que tu é metida, isso que tu é! [...] Tu é que se acha, tu se acha melhor que todo mundo, tu é superior a todo mundo!

Jéssica: Não me acho melhor não, Val, só não me acho pior, "entendesse"? É diferente.

Na cena, percebemos "a importância da arquitetura na reprodução das relações coloniais dentro da residência" (MAICH, 2015, p. 146), visto que a demarcação espacial das casas é um resquício colonial, do tempo em que os cômodos destinados à família patriarcal ficavam dentro das casas e eram separados da cozinha e da área de serviço por pelo menos um cômodo, como a copa. Enquanto as construções externas "eram destinadas aos animais e aos empregados, os quartos das criadas ficavam aos fundos, junto à cozinha" (DA SILVA PINTO, 2017).

Pode-se observar a empregada doméstica a partir do conceito de estraneidade (CANCLINI, 2016), no qual o ser estrangeiro pode tomar várias dimensões, não apenas o de ser migrante, como também ser estranho na sua própria cidade: seja através da migrante nordestina Val que mora há anos na casa dos patrões em São Paulo, seja por meio da empregada Ladjane, moradora da periferia, que muito provavelmente só circulam em determinados locais da cidade por conta do trabalho. O espaço urbano não pode ser desfrutado por inteiro, por elas serem atravessadas pela "arte da diferença" (CANCLINI, 2016) perante a mobilidade. Ladjane não frequenta a praia de Boa Viagem todas as manhãs como sua patroa; $V a l$ em seus momentos de lazer busca locais que remetam a sua cidade natal, como bailes de forró, acompanhada de outros migrantes nordestinos.

\section{Considerações finais}

A interação entre as patroas e empregadas é marcada por signos materiais de distinção: diferenciação entre o sorvete da família e da empregada ${ }^{11}$, o lugar de descanso da empregada e dos patrões, a piscina vetada ao uso da empregada. Contudo, há também a dimensão invisível localizada e hierarquizada pelas expressões de afeto. Para ser considerada boa patroa, Clara tem que ir à festa de Ladjane, e Bárbara tem que receber Jéssica.

11 Em Que horas ela volta Fabinho tem o sorvete premium que só ele e a família podem tomar. Jéssica toma o sorvete de Fabinho, não o popular destinado às empregadas, e tal gesto deflagra uma crise. 
Mas Val e Ladjane devem se sentir agradecidas e demonstrar tal sentimento com fidelidade às patroas. Marcel Mauss (2003) apontou como os sistemas de troca atuam como linguagem em que os objetos se tornam signos marcadores das posições entre quem recebe e quem doa. Espera-se que os patrões ofereçam presentes. Por outro lado, os empregados devem retribuir com gratidão, que tem um 'gosto de servidão'. "Mostrando-se grata, a empregada confirma a existência de uma hierarquia e conforma-se ao seu status inferior, aceitando aquele estado de 'servidão perpétua' tão odioso aos iguais" (COELHO, 2001, p. 275).

As relações entre patroas e empregadas nos ajudam a pensar como as práticas arcaicas convivem lado a lado com ideais modernos de igualdade e justiça. Aquarius (2016) mostra que Pernambuco, como metonímia do Brasil, continuará sendo hierárquico nas suas relações. Que horas ela volta?, lançado um ano antes, vislumbra o sonho (interrompido) de um Brasil mais igualitário. Afinal, Jéssica chega à casa dos patrões de sua mãe já inserida no contexto social de um Brasil que, naquele momento, possibilitava a ascensão social para as classes trabalhadoras através da entrada na universidade. Por conta disso, questiona as estruturas de dominação nas quais sua mãe está imersa, reivindica o tratamento igualitário e, deste modo, desorganiza o discurso fantasioso do "quase como se fosse da família", que encobre a relação hierárquica e ambígua embalada por expressões de afeto.

Maurício de Bragança é professor adjunto do Programa de Pós-Graduação em Cinema eVideo da Universidade Federal Fluminense e doutor em Letras.

mauriciode@yahoo.com

Tatiana Oliveira Siciliano é professora adjunta do Departamento de Comunicação e do PPGCOM da Pontifícia Universidade Católica do Rio de Janeiro e doutora em Antropologia Social.

tatios@terra.com.br

Licia Marta Da Silva Pinto é doutoranda do Programa de Pós-Graduação em Cinema e Vídeo da Universidade Federal Fluminense; mestre em Comunicação pelo PPGCOM da PUC-Rio.

liciams.pinto@gmail.com 


\section{Referências}

ALMEIDA, M. S. K. Entre nós mulheres, elas as patroas e elas as empregadas. In: Colcha de retalhos: estudos sobre a família no Brasil. São Paulo: Brasiliense, 1982.

AQUARIUS. Direção: Kleber Mendonça Filho. Produção: Emilie Lesclaux, Michel Merkt, Said Ben Said. Coprodução: Walter Salles. Brasil/França: CinemaScópio, SBS Productions, Videofilmes, Globo Filmes, 2016

BOURDIEU, P. O poder simbólico. Rio de Janeiro: Bertrand Brasil, 2000.

A distinção: crítica social do julgamento. Porto Alegre: Zouk, 2015.

BRITES, J. Afeto e desigualdade: gênero, geração e classe entre empregadas domésticas e seus empregadores. Cadernos Pagu, Campinas, n.29, p.91-109, 2007.

CANCLINI, N. G. O mundo inteiro como lugar estranho. São Paulo: Editora da Universidade de São Paulo, 2016.

COELHO, M. C. Sobre agradecimentos e desagrados: trocas materiais, relações hierárquicas e sentimentos. In: Mediação, Cultura e Política. Rio de Janeiro: Aeroplano, 2001.

DAVIS, A. Mulheres, raça e classe. São Paulo: Boitempo Editorial, 2016.

DA SILVA PINTO, L. M. Dia de Empreguete, Véspera de Madame: A mudança na representação ficcional das empregadas domésticas a partir da PEC 66/2012. Dissertação (Mestrado em Comunicação) - Pontifícia Universidade Católica (PUC Rio), Rio de janeiro, 2017.

FIGUEIRA, S. O moderno e o arcaico na nova família brasileira: notas sobre a dimensão invisível da mudança social. In: Uma nova família? O moderno e o arcaico na família de classe média brasileira. Rio de Janeiro: Jorge Zahar Editora, 1987.

FIGUEIREDO, V. L. F. A partilha do espaço urbano e a questão do outro próximo: repercussões no discurso teórico e na ficção cinematográfica. Galáxia, São Paulo, n. 24, p 103-114, 2012.

GOMES, R. C. e SICILIANO, T. Rastros, cupins e câncer: tensões urbanas na era de Aquarius Ecos midiáticos de processos de gentrificação. Trabalho apresentado ao Grupo de Trabalho Cultura das Mídias do XXVI Encontro Anual da Compós, Faculdade Cásper Líbero, São Paulo - São Paulo, 2017.

HAESBAERT, R. Territórios em Disputa: desafios da lógica espacial zonal da luta política. CampoTerritório: revista de geografia agrária. Porto Alegre: v. 9, n. 18, p. 1-17, 2014.

KOFES, S. Mulher, mulheres: identidade, diferença e desigualdade na relação entre patroas e empregadas domésticas. Campinas: Unicamp, 2001.

LANA, L. Da porta da cozinha para lá: gênero e mudança social no filme Que horas ela volta?.

Rumores, São Paulo, vol. 10, n.19, p.21-137, 2016.

MAICH, K. Geografias da desigualdade: trabalhadoras domésticas peruanas navegam por espaços de servidão. In: Doméstica. Recife: Desvia Produções, 2015.

MASSEY, D. Um sentido global do lugar. In: O espaço da diferença. Campinas: Papirus, 2000.

MAUSS, M. Ensaio sobre a dádiva. In: Sociologia e Antropologia. São Paulo, Cosac \& Naif, 2003.

QUE HORAS Ela Volta? Direção: Anna Muylaert Produção: Anna Muylaert, Caio Gullane, Débora Ivanov, Fabiano Gullane. Brasil: Pandora Filmes, 2015.

QUIJANO, A. Colonialidade do poder, eurocentrismo e América Latina In: A colonialidade do saber: eurocentrismo e ciências sociais. Perspectivas latino-americanas. Buenos Aires: CLACSO, 2005. 
RIBEIRO, D. O que é lugar de fala? Belo Horizonte: Letramento, 2017.

SILVEIRA, L. M. B. Como se fosse da família. A relação (in) tensa entre mães e babás. Rio de Janeiro: E-papers FAPERJ, 2014.

SOUZA, J. Senso comum e justificação da desigualdade. In: Ralé Brasileira: quem é e como vive. Belo Horizonte: Editora UFMG, 2009.

TRIGUEIRO, E.; CUNHA, V. O quarto da empregada: história de uma apartheid imutável num espaço doméstico em mudança. In: Doméstica. Recife: Desvia Produções, 2015.

Artigo recebido em 16/01/2019

e aprovado em 12/03/2019. 